\title{
A Field Study of Atmospheric Corrosion of Carbon Steel after Short Exposure in Pelabuhan Ratu, West Java Province, Indonesia
}

\author{
Gadang PRIYOTOMO ${ }^{1, *}$, Siska PRIFIHARNI ${ }^{1}$, Lutviasari NURAINI ${ }^{1}$, \\ Joko TRIWARDONO ${ }^{1}$, Ahmad ROYANI ${ }^{1}$, Sundjono $^{1}$, \\ Ibrahim PURAWIARDI ${ }^{1}$ and Hadi GUNAWAN ${ }^{2}$
}

\author{
${ }^{1}$ Research Center for Metallurgy and Materials - Indonesian Institute of Sciences, \\ Kawasan Puspiptek 470 Tangerang Selatan Banten, 15314, Indonesia \\ ${ }^{2}$ Research Center and Development of Roads and Bridge, Indonesia's Ministry of Public Works and \\ Housing Jl. A.H. Nasution No.264, Bandung, West Java, 40294, Indonesia
}

('Corresponding author's e-mail: gadangp@gmail.com)

Received: 17 March 2020, Revised: 16 March 2021, Accepted: 23 March 2021

\begin{abstract}
The investigation of atmospheric corrosion of mild carbon steel as representative of offshore infrastructure has been carried out in the marine tropical of Pelabuhan Ratu, West Java, Indonesia. They are exposed up to 76 days of periods, and their corrosion rates are determined according to ASTM G1-03. The surface morphology, the elemental compositions and compounds were observed using a scanning electron microscope (SEM), energy dispersive spectroscopy (EDS) and X-ray diffraction (XRD), respectively. The environmental parameters of the test site are monitored during exposure, such as air temperature, relative humidity $(\mathrm{RH})$, airborne salinity and dew temperature. Based on the results, the corrosion rates of steels were 2.79 and $2.8 \mathrm{mpy}$ within the 27 and 76 days exposures, respectively. The presence of chloride deposition on the surface of steel can increase the severity of corrosion. Moreover, the detrimental effect of chloride was observed in rust product, which was covered by an oxygen element. The main phases of rust products present were magnetite $\left(\mathrm{Fe}_{3} \mathrm{O}_{4}\right)$ and hematite $\left(\alpha-\mathrm{Fe}_{2} \mathrm{O}_{3} \cdot \mathrm{H}_{2} \mathrm{O}\right)$. Several cracks were observed in the rust layer, which tended to exfoliate and lose adherence and protectiveness from further corrosion attack.
\end{abstract}

Keywords: Carbon steel, Atmospheric corrosion, Coastal region, Relative humidity, Chloride deposition

\section{Introduction}

The atmospheric corrosion of metal is an electrochemical process, which sums up the wet and dry processes when an electrolyte layer forms and attaches to the surface of the metal. The percentage of metallic structure degradation yielded by atmospheric corrosion attack is around $80 \%$. The results of the atmospheric circumstances, which correspond to corrosion of metals, are complicated to elaborate. In addition, the corrosion rates of the metal also vary in function of global seasons, daily time and various geographic regions. The environment parameters, such as aqueous precipitation (rain, fog, etc.) and high relative humidity $(\mathrm{RH})$ can lead to the increase of metallic corrosion in the atmosphere [1]. Therefore, the complexity of environment parameters, that tends to change each period, is not easy to simulate in the laboratory for atmospheric corrosion-testing purposes. Therefore, all atmospheric corrosion tests must be carried out in outdoor exposure sites.

Moreover, the effect of pollutants, such as chloride and sulfur can enhance significantly the corrosion attack [2]. Sundjono et al. [3] and Priyotomo et al. [4] showed the detrimental effect of chloride with the increase of corrosion attack on carbon steel as represent of offshore structure. Furthermore, in the 
marine atmosphere, the main role of chloride refers to the atmospheric salinity. Atmospheric salinity in coastal regions yields atmospheric corrosion, which is compared to rural or urban atmosphere. The combination of chloride ion and the moisture layer increases the conductivity of electrolyte film on the metal surface and damages the protective rust product [5]. The atmospheric corrosion rate has been reported that the synergistic high relative humidity and chloride factors were higher than 1 factor [6]. Furthermore, many researchers investigated the marine atmospheric corrosion behavior of steel considering the environmental factors of temperature, relative humidity (RH), chloride, and so on in tropical regions [6-8]. In northern west java, Indonesia, as a local part of the tropical region, Nuraini and co-workers focused on the chloride factor that influences the atmospheric corrosion process in this coastal area [8], but there was no explanation of synergistic $\mathrm{RH}$ and chloride.

However, with regard to offshore structural steel, there is little study on its atmospheric corrosion in the southeast Asia region, particularly from the southern coast of West Java, Indonesia. Therefore, the objective of the present work is to elucidate the atmospheric corrosion behavior of steel which induced the environmental factors in tropical coastal regions.

\section{Materials and methods}

\section{The specimen preparation}

In this present work, the carbon steel received was in a plate shape for atmospheric test specimens. This was cut into $15 \times 7.5 \times 0.3 \mathrm{~cm}^{3}$. The pickling treatment was carried out in those specimens, which were referred to as ASTM G-1 before exposure. During the exposure, the observation of corrosion behavior was only in 1 side of the upper surface, while the back side was covered with adhesive tape. There were 3 specimens of carbon steel that were installed in a panel of atmospheric corrosion test with time interval exposure. The purpose of the installation of the 3 specimens in each interval time is to make ensure the reliability of the results and to calculate the corresponding corrosion rate of the metal. The duration of the test exposure was up to 76 days. The specimens were installed at a $45^{\circ}$ angle from a horizontal axis facing toward the sea. The chemical compositions of the specimen are shown in Table $\mathbf{1}$ as well as in the proceeding work [8].

Table 1 The chemical composition of carbon steel (wt.\%) [8].

\begin{tabular}{ccccccccc}
\hline $\mathbf{F e}$ & $\mathbf{S i}$ & $\mathbf{P}$ & $\mathbf{M n}$ & $\mathbf{N i}$ & $\mathbf{C r}$ & $\mathbf{C u}$ & $\mathbf{T i}$ & $\mathbf{C}$ \\
\hline 99.25 & 0.11 & 0.02 & 0.29 & 0.01 & 0.30 & 0.01 & 0.01 & 0.13 \\
\hline
\end{tabular}

\section{The location of exposure test}

The severity of tropical atmospheric corrosion tends to vary significantly among various geographic regions. With regards to the subject of the present work, the exposure site was located in the coastal area of Pelabuhan Ratu Region, West Java Province, Indonesia as shown in Figure 1A. The average distance of the bridges from coastline is around $200 \mathrm{~m}$. Moreover, the chloride deposition rate was determined by wood rectangular collector, which consists of cross stitch cloth in the dimension of $10 \times 10 \mathrm{~cm}^{2}$ as shown in Figure 1B. The airborne salt was trapped in that collector during exposure. The measurement of the chloride deposition was carried out by $\mathrm{HACH}$ chloride titrator strips kit. In addition, the measurement of relative humidity and temperature was also performed each hour during the exposure. 

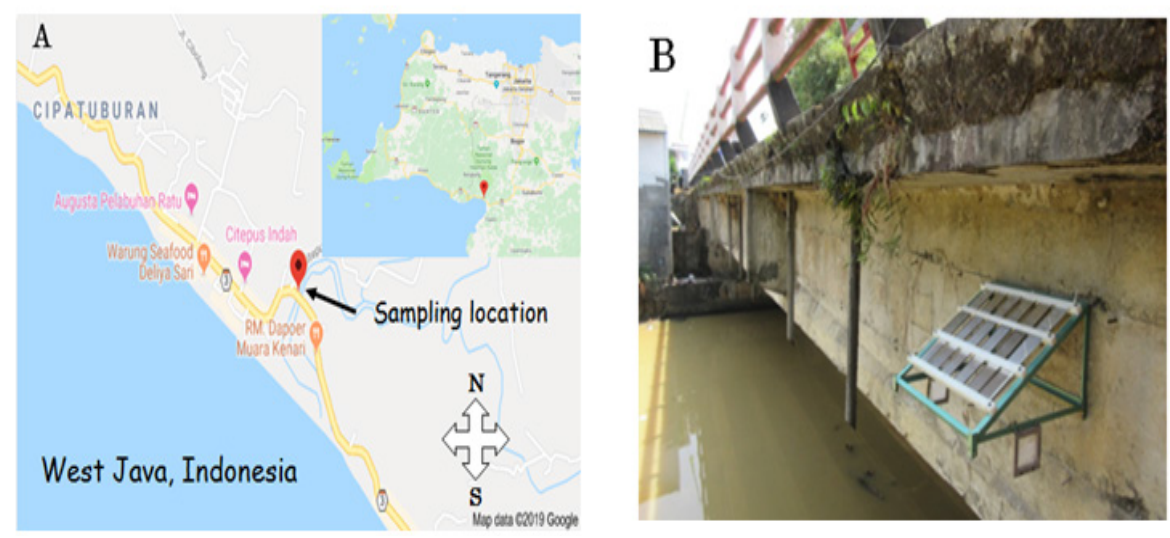

Figure 1 (A) Location of the exposure site in Pelabuhan Ratu, Northern West Java, Indonesia, (B) The test rack of atmospheric corrosion.

\section{Characterization and analysis of corroded specimens}

At a certain period, the corroded specimens were retrieved from the exposure tests site, and were analyzed in the laboratory. The specimens were cleaned and pickled to remove the corrosive products on the surface, which refers to as ASTM G-1(03) 2017. The corrosion rates of each specimen were measured based on the weight loss method. This method was preceded with calculating weight loss of specimens before and after the exposure. The corrosion rate was calculated from the weight loss using the following formula:

$\mathrm{CR}=\Delta \mathrm{W} \cdot \mathrm{K} / \mathrm{d} \cdot \mathrm{A} \cdot \mathrm{t}$

Where $\mathrm{CR}=$ Corrosion rate in mills per year (mpy); $\Delta \mathrm{W}=$ Weight loss in grams; $\mathrm{K}=$ Constant; $\mathrm{d}=$ metal density in $\mathrm{g} / \mathrm{cm}^{3} ; \mathrm{t}=$ exposure time (day). The morphology of corroded surface, the distribution of elemental composition for rust product and various phase of corrosion products were identified by scanning electron microscopy (SEM), energy dispersive spectroscopy (EDS) and X-ray diffraction (XRD), respectively.

\section{Results and discussion}

\section{Corrosion rates of carbon steels}

Figure 2 shows the Corrosion rate of a mild steel as a function of exposure time in Pelabuhan Ratu region, West Java. The present results revealed that the corrosion rate (CR) for 27 days was higher when compared with their exposure for 76 days. The atmospheric corrosion value of steel was 3.39 mpy for 1 month exposed in Limbangan region, West Java [8], where the magnitude of the CR is higher than that in the present results. The impact of the distance from the sea constitutes one of the most essential factors of atmospheric corrosion in coastal areas. In other words, the closer the position of the test site to the coastline, the higher the corrosion rate [9]. The position of the test site in Limbangan [8] and Pelabuhan Ratu was around 100 and $200 \mathrm{~m}$ from coastline, respectively. 


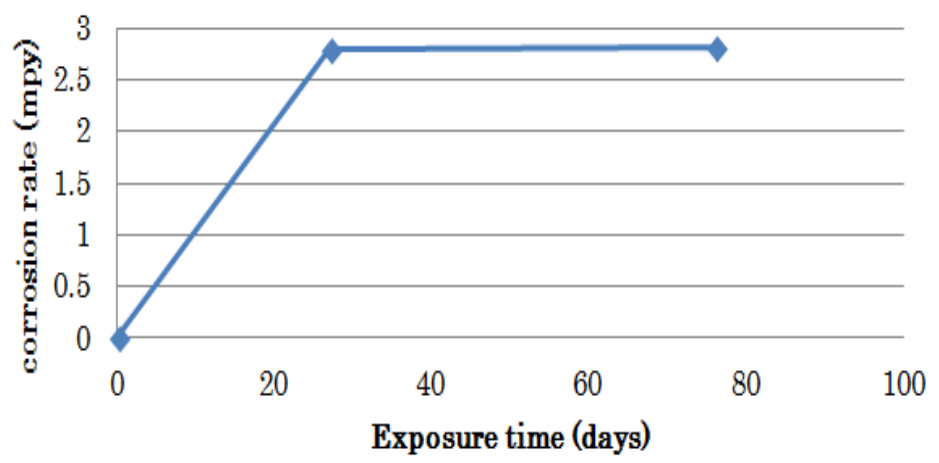

Figure 2 Corrosion rate of steel as function of exposure time in Pelabuhan Ratu region, West Java, Indonesia.

In the previous section, the severity of corrosion attack mainly depends on the exposure time and some climatic parameters, such as relative humidity $(\mathrm{RH})$, temperature $(\mathrm{T})$, sulfur content, and salinity (chloride) [9]. The presence of thin film of an electrolyte can create on metallic surface of metal when exposed to a critical level humidity $\left(\mathrm{RH}_{\text {crit }}\right)$ [10]. The electrochemical process begins to corrode slowly in a marine-coastal environment at a $\mathrm{RH}_{\text {crit }}$ value of $60 \%$ [11], but the corrosion rate increases sharply ay $75-80 \%$ RH [12]. Figure 3 shows the relationship of daily relative humidity (RH) variation as function of the time exposure in Pelabuhan Ratu region. Based on the results, RH is high at midnight but in the early morning, it drops quickly, after the sun rises. This goes on until after midday for each day of the exposure. As shown in Figure 3 (dashed line), in all of the exposure times, there are more than $95 \%$ of $\mathrm{RH}_{\text {crit }}$ values above $60 \%$. This condition initiates and generates the electrochemical process on the surface of steel, where it leads to the increase of corrosion attack.

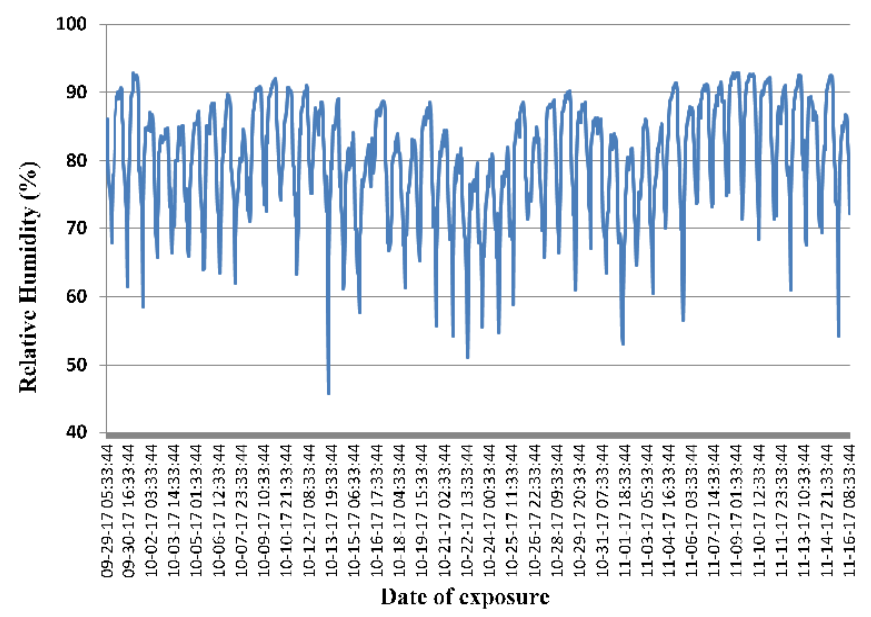

Figure 3 The relationship of daily relative humidity $(\mathrm{RH})$ variation as function of time exposure.

Figure 4 shows the relationship of ambient temperature and dew temperature as a function of time exposure. Based on the result, ambient air temperature is low at midnight, decreasing in the early morning hours, and then increasing quickly until just after midday for each day of the exposure. The dew point correlated with the temperature at which condensation occurs on the surface of carbon steel. The high 
magnitude of RH is associated with a dew point close to ambient air temperature. There is no corrosion at air temperature above $10-15{ }^{\circ} \mathrm{C}$ from the dew point [13]. However, during all time exposure for the test, the difference between air temperature and the dew point was below $10^{\circ} \mathrm{C}$. This difference occurs from midnight to morning, which tends to condense on the surface of specimens. The condensation process leads to the increase of electrochemical reaction on the surface, in which corrosion occurs simultaneously.

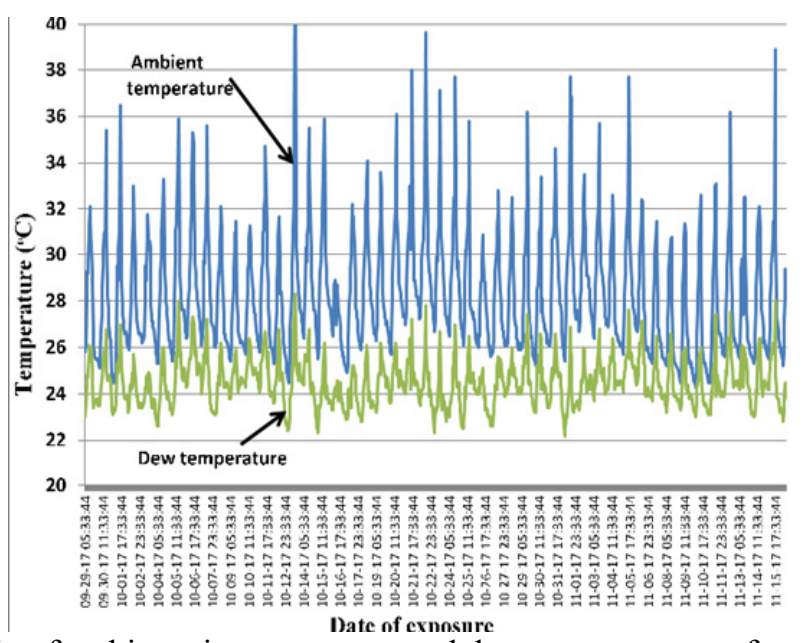

Figure 4 The relationship of ambient air temperature and dew temperature as function of time exposure.

\section{Morphological characterization of corroded steel after exposure}

Figure 5 shows the surface appearance of the specimen before and after the exposure in Pelabuhan Ratu region, West Java. After various exposures, the rust products were covered uniformly on the whole surface of specimens. The distributions of corrosion products were denser with an increasing time exposure, where the higher corrosion rate of steel leads the denser rust product.
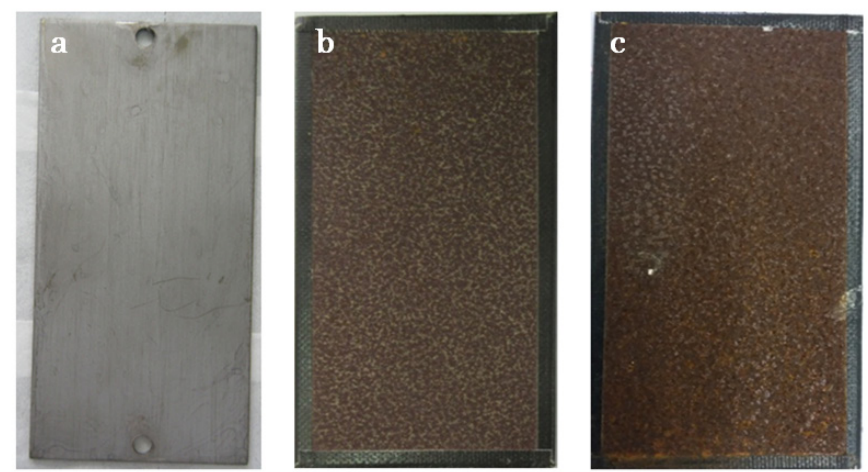

Figure 5 The surface appearances of specimen a) before exposure, b) 27 days after exposure, c) 76 days after exposure.

Figures 6a and $\mathbf{6 b}$ show the morphology of rust product on steel surface after 27 and 76 days of exposures. It is shown that the specimen is completely covered by a large amount of rust product in both time exposures. The rust product was heterogeneous in nature at certain locations. Likewise, the rust product was cracked, while nodular (doughnut) structures were composed of flowery needle-like rust growing on top of a cracked rust product. The area of needle growth was indicated as site of the cracking 
of outer oxide rust layer. However, there are many cracks in the rust products that allow entry of chloride from airborne salts. This implies that the increase of corrosion rate corresponds to the presence of crack in rust layer [14]. In addition, in coastal atmosphere, the rust layers are commonly formed with a heavy cracking that tends to exfoliate and become partly or completely detached from the base metal [1].
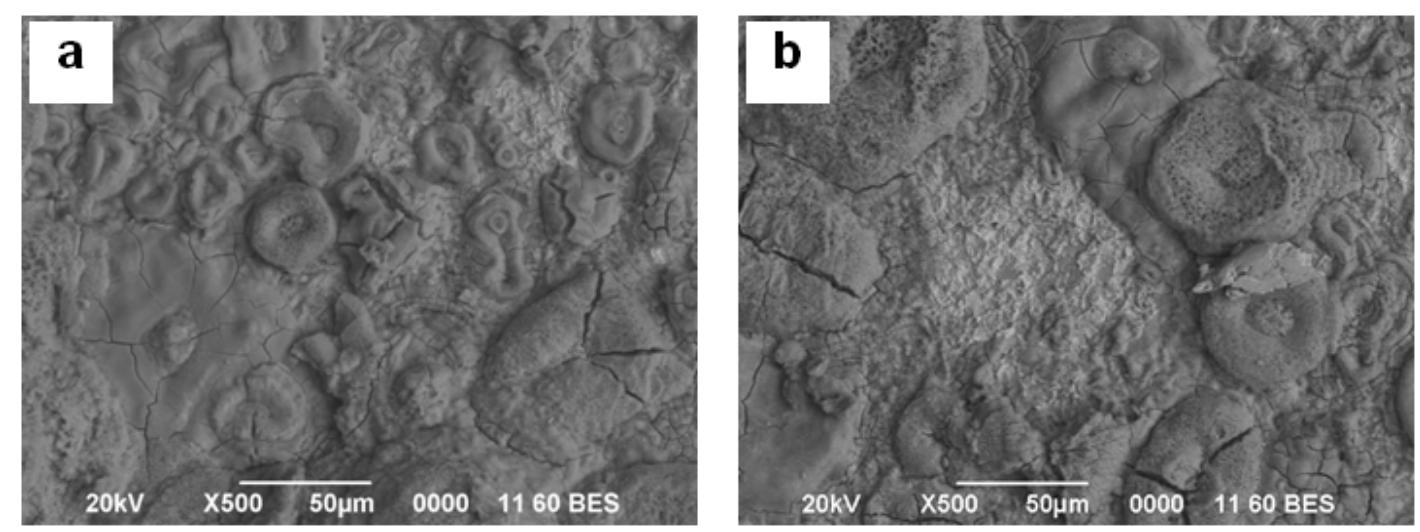

Figure 6 Morphology of rust product on corroded steel after exposure of a) 27 days and b) 76 days.

The distribution of carbon steel elements before and after being corroded is shown in Figures 7 and $\mathbf{8}$, respectively. There are large amounts of oxygen $(\mathrm{O})$ which were distributed on the surface. The highest amount of ferrous (Fe) was distributed in the whole surface as shown in Figures 7 and 8. After the exposure, the small amount of chloride was spread uniformly. The role of the chloride ion from airborne salts is essential to induce the corrosion attack by electrochemical reaction on steel. Chloride ion competes with hydroxyl ions to combine with ferrous cations generated in the anodic reaction [2]. In cathodic reaction, the presence of hydroxyl ions tends to produce stable rust product, which serves as a protective layer for further corrosion attack. However, the combination of the chloride concentration in the aqueous layer deposited on the metal and the high moisture retention in very deteriorated areas of the rust give rise to the formation of soluble ferrous chloride $\left(\mathrm{FeCl}_{2}\right)$, which hydrolyses the water, according to reactions $[1,2]$.

$$
\begin{aligned}
& \mathrm{Fe}^{2+}+\mathrm{H}_{2} \mathrm{O} \rightarrow \mathrm{FeOH}_{\mathrm{ads}}+\mathrm{H}^{+}+\mathrm{e} \\
& (\mathrm{FeOH})_{\mathrm{ads}}+\mathrm{Cl}^{-} \rightarrow(\mathrm{FeCl})_{\mathrm{ads}}+\mathrm{OH}^{-} \\
& (\mathrm{FeCl})_{\mathrm{ads}} \rightarrow \mathrm{Fe}^{2+}+\mathrm{Cl}^{-}+\mathrm{e}
\end{aligned}
$$

Furthermore, the formation of the crack on rust product tends to lead to pitting attack underneath rust product [2]. Based on the results, the uniform distribution of the chloride can tend to increase the production of ferrous chloride $\left(\mathrm{FeCl}_{2}\right)$ in high $\mathrm{RH}$ condition and the aqueous layer deposited on the metal. The hydrolysis of $\mathrm{FeCl}_{2}$ took place, leads to the rise of the acidity of the electrolyte according to reaction $[2]:$

$\mathrm{FeCl}_{2}+\mathrm{H}_{2} \mathrm{O} \rightarrow \mathrm{FeO}+2 \mathrm{HCl}$ 

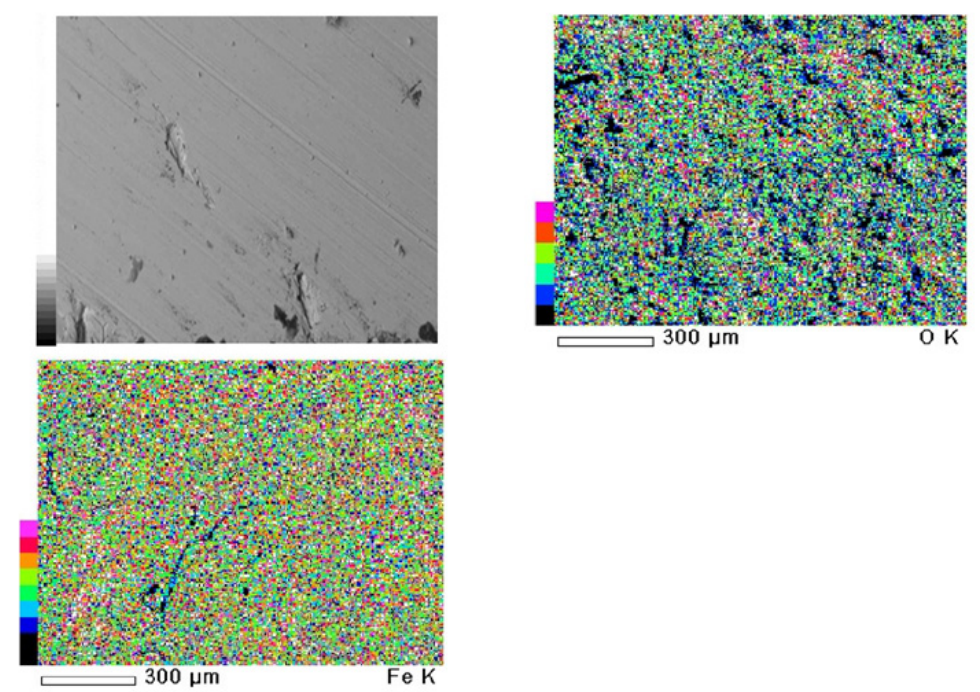

Figure 7 Element distribution of corroded carbon steel before the exposure, (a) SEM, (b) O, (c) Fe.
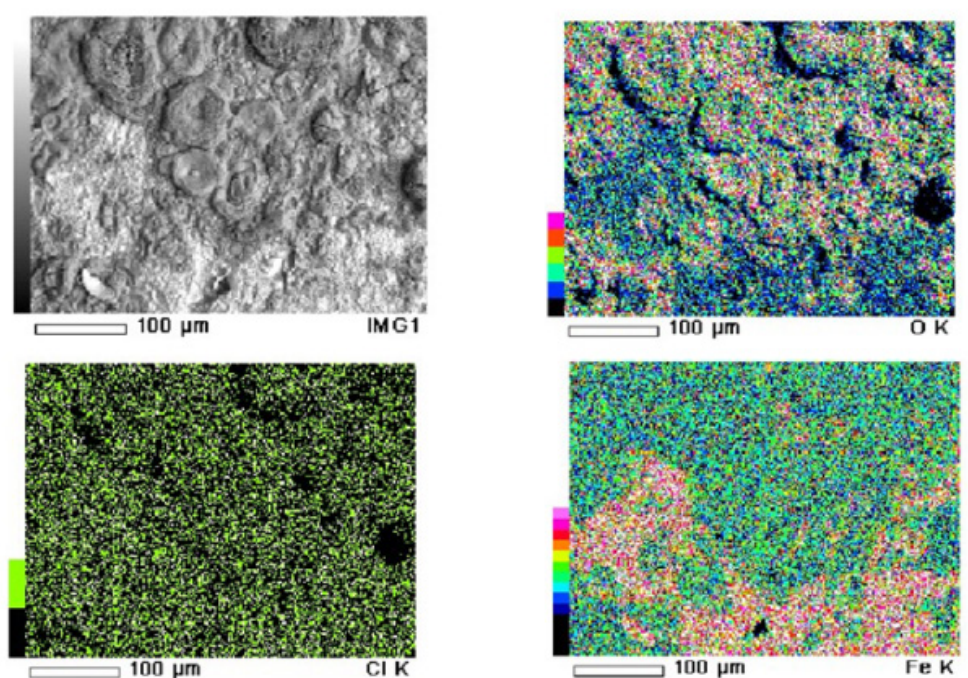

Figure 8 Element distribution of corroded carbon steel after the exposure time of 27 days, (a) SEM, (b) O, (c) $\mathrm{Cl}$, (d) $\mathrm{Fe}$.

There are common phases of corrosion product in all X-ray diffractograms (XRD) obtained. Carbon steel is predominant in lepidocrocite $(\gamma-\mathrm{FeOOH})$, goethite $(\alpha-\mathrm{FeOOH})$ and hydrated maghemite $\left(\gamma-\mathrm{Fe}_{2} \mathrm{O}_{3} \cdot \mathrm{H}_{2} \mathrm{O}\right)$ [17]. Figure 8 shows XRD spectrum specimens exposed in Pelabuhan Ratu for 76 days. The result of XRD test shows 2 phases, consisting of hematite $\left(\alpha-\mathrm{Fe}_{2} \mathrm{O}_{3} \cdot \mathrm{H}_{2} \mathrm{O}\right)$ and Magnetite $\left(\mathrm{Fe}_{3} \mathrm{O}_{4}\right)$. Santana Rodriguez and co-workers reported that the presence of akaganeite $(\beta-\mathrm{FeOOH})$ as primary phase was yielded in marine coastal environment $[16,17]$. However, such findings were not reflected in the current study. Moreover, Morcillo and co-workers also reported that in the severe marine atmospheres (high salinity airborne), high akaganeite contents were found in the rust, and the magnetite content was also higher than that found in atmospheres of lower salinity [1]. In the current study, there is no akaganeite phase, and the phase of magnetite is present clearly due to a lower average salinity deposition 
$\left(24.335 \mathrm{mg} / \mathrm{m}^{2}\right.$.day). Large magnetite formations have been found on the underlying steel that had lost the previously formed rust layer due to exfoliation [17].

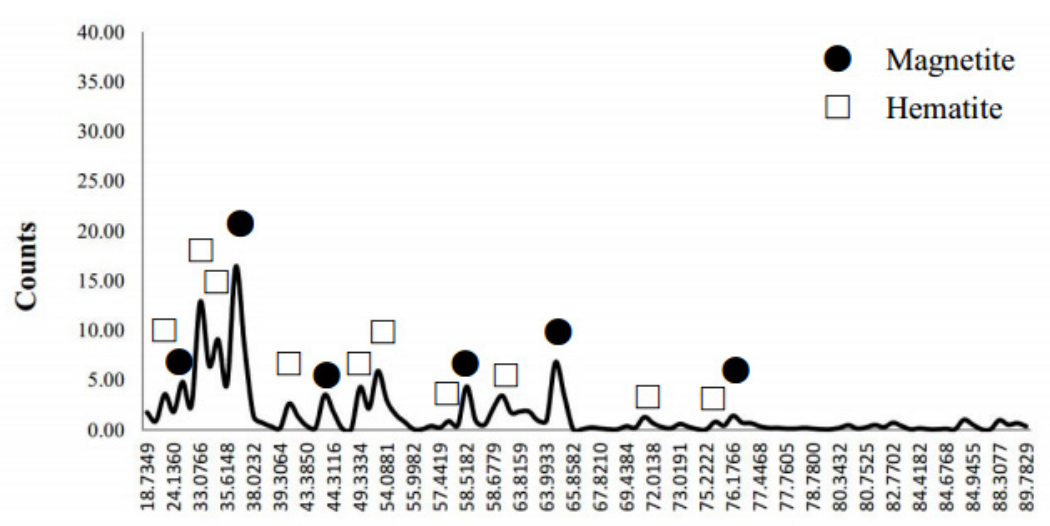

$2 \theta$

Figure 9 XRD spectrum specimens exposed in Pelabuhan Ratu region in 27 days.

Furthermore, in short-term atmospheric corrosion, magnetite $\left(\mathrm{Fe}_{3} \mathrm{O}_{4}\right)$ phase was identified in chloride airborne condition [19] as well as in the present study. The presence of magnetite occurs after the phase transformation of lepidocrocite on prolonged time exposure in marine environments [20,21]. Other investigations reported that the presence of magnetite layer contributes in minimizing further corrosion attack due to adherent and protective oxide layer on steel [22-24]. Therefore, it implies that the corrosion rate tends to decrease in long-term exposure period. However, this was not found in the current study.

\section{Conclusions}

In Pelabuhan Ratu Region as a representative of the tropical atmosphere, the corrosion of the carbon steel took place due to the high humidity surface layer and chloride ions. It was found that the phases of rust product are typical of magnetite and hematite in all time exposure. There is no akaganeite in the oxide layer due to a low chloride concentration. However, there were many cracks in the rust layer that tend to exfoliate and lose adherence and protectiveness for further corrosion attack.

\section{Acknowledgements}

The authors would like to acknowledge the financial support given by the Research Center for Metallurgy and Material, Indonesian Institute of Sciences.

\section{References}

[1] M Morcillo, J Alcántara, I Díaz, B Chico, J Simancas and DDL Fuente. Marine atmospheric corrosion of carbon steels. Rev. Metal. 2015; 51, e045.

[2] GE Badea, P Cret, M Lolea and A Setel. Studies of carbon steel corrosion in atmospheric conditions. Acta Tech. Corviniensis Bull. Eng. 2011; 4, 25-8.

[3] G Priyotomo, L Nuraini, S Prifiharni and Sundjono. Corrosion behavior of mild steel in seawater from Karangsong \& Eretan of West Java Region, Indonesia. J. Kelautan Indonesian J. Mar. Sci. Tech. 2018; 11, 184-91. 
http://wjst.wu.ac.th

[4] S Sundjono, G Priyotomo, L Nuraini and S Prifiharni. Corrosion behavior of mild steel in seawater from Northern Coast of Java and Southern Coast of Bali, Indonesia. J. Eng. Tech. Sci. 2017; 49, 770-84.

[5] M Morcillo, B Chico, J Alcantara, I Diaz, J Simancas and DDL Fuente. Atmospheric corrosion of mild steel in chloride-rich environments Questions to be answered. Mater. Corrosion 2015; 66, 88292.

[6] T Khaing, YYK Win and NM Kyaw. Study on rust characterization and prediction of atmospheric corrosion rates for structural steels in Yangon (Myanmar). In: Proceedings of the $3^{\text {rd }}$ International Conference on Civil Engineering Research, Surabaya, Indonesia. 2017, p. 143-8.

[7] P Castro-Borges and L Veleva. Time of wetness and HR-T complex as tools for corrosion risk evaluation in a concrete block exposed to a humid tropical environment. J. Construct. 2015; 14, 6571.

[8] L Nuraini, S Prifiharni, G Priyotomo, Sundjono, H Gunawan and I Purawiardi. Atmospheric corrosion performance of different steels in early exposure in the coastal area region West Java, Indonesia. AIP Conf. Proc. 2018; 1964, 020040.

[9] S Feliu, M Morcillo and B Chico. Effect of distance from sea on atmospheric corrosion rate. Corrosion 1999; 55, 883-91.

[10] PR Roberge. Hand Book of Corrosion Engineering. McGraw-Hill, New York, 2000.

[11] P Castro-Borges and L Veleva. Time of wetness and HR-T complex as tools for corrosion risk evaluating in a concrete block exposed to a humid tropical environment. J. Construct. 2015; 14, 6571.

[12] ZW Li, NJ Marston and MS Jones. Update of New Zealand's atmospheric corrosivity map. Branz, Judgeford, 2013.

[13] RW Revie. Uhlig's Corrosion Handbook. John Wiley \& Sons, Ontario, 2011.

[14] R Vera and S Ossandón. On the prediction of atmospheric corrosion of metals and alloys in chile using artificial neural networks. Int. J. Electrochem. Sci. 2014; 9, 7131-51.

[15] NG Smart, M Gamboa, JOM Bockris and J Aldeco. Corrosion mechanism of iron in concentrated acidic zinc chloride media. Corrosion Sci. 1993; 34, 759-77.

[16] RA Antunes, I Costa and DLAD Faria. Characterization of corrosion products formed on steels in the first months of atmospheric exposure. Mater. Res. 2003; 6, 403-8.

[17] JJS Rodriguez, FJS Hernandez and JEG Gonzalez. XRD and SEM studies of the layer of corrosion products for carbon steel in various different environments in the province of Las Palmas (The Canary Islands, Spain). Corrosion Sci. 2002; 44, 2425-38.

[18] A Raman, S Nasrazadani and L Sharma. Morphology of rust phases formed on weathering steels in various laboratory corrosion tests. Metallography 1989; 22, 79-96.

[19] JA Jaen, J Iglesias and C Hernandez. Analysis of short-term steel corrosion products formed in tropical marine environments of Panama. Int. J. Corrosion 2012; 2012, 162729.

[20] J Alcántara, B Chico, I Díaz, DDL Fuente and M Morcillo. Airborne chloride deposit and its effect on marine atmospheric corrosion of mild steel. Corrosion Sci. 2015; 97, 74-88.

[21] BYR Surnam, CW Chui, H Xiao and H Liang. Investigating atmospheric corrosion behavior of carbon steel in coastal regions of Mauritius using Raman spectroscopy. Matéria (Rio J.). 2016; 21, 157-68.

[22] MM Barneya, BP Embaid and A Nissan. Identifying phases in protective scale formed during high temperature corrosion. Corrosion Sci. 2017; 127, 21-6.

[23] $\mathrm{P}$ Jin and S Nesic. Mechanism of magnetite formation in high temperature naphthenic acid corrosion by crude oil fractions. Corrosion Sci. 2017; 115, 93-105.

[24] LTH Lien and HL Hong. Characteristics of corrosion product layer formed on weathering steel exposed to the tropical climate of Vietnam. Mater. Sci. Appl. 2013; 4, 6-16. 